869.0 Vicente G. 7 Quem tem farelos? .06

\title{
ESTUDIOS SOBRE EL TEATRO DE GIL VICENTE: OBRAS DE CRITICA SOCIAL Y RELIGIOSA (CONTINUACION)
}

\author{
Stanislav Zimic
}

III.

\section{QUEM TEM FARELOS?}

Los críticos admiran Quem Tem Farelos? por su »gaiety and concentration " que la hacen "perhaps the best of the farses [de Gil Vicente] "1 por su "freschezza che il pensiero spontaneamente ricorre alla zampillante gioiosità di un Mozart e di un Rossini «"; por su "comiciadade austera ${ }^{3}$, etc. Por otra parte, esta magnífica farsa se censura a menudo por su »enredo muito tenue«, por "a quase inexistência de intriga «"; por el »ingénuo arranjo dos seus quadros« y porque les falta »ordenação aos agrupamentos e naturalidade ao desfile episódico « ${ }^{5}$. En un libro reciente sobre las farsas gilvicentinas se concluye que "although there is a weak semblance of structural balance in this play, it is, for the writer, the least effective of the farsas examined « ${ }^{6} \mathrm{La}$ supuesta debilidad o incoherencia de la estructura dramática, la falta aparente de una estrecha y lógica relación, tanto desde el punto de vista temático como artístico, entre los varios núcleos episódicos es, según se desprende de las opiniones citadas arriba, la razón principal por la cual Quem Tem Farelos? les parece tan dispar en sus cualidades a muchos críticos. En particular, en el contexto de la sátira de ese patético tipo social, el escudero, que constituye, en opinión unánime de la crítica, el propósito principal de la obra, ${ }^{7}$ ¿qué función dramática desempeña precisamente la escena final del altercado

1 Aubrey F. G. Bell, Gil Vicente (Oxford University Press, 1921), p. 50. p. 407 .

Enzio de Poppa Vólture, Gil Vicente: Teatro (Firenze: Sansoni, 1957), Vol. II,

${ }^{3}$ Arlindo de Soussa, Pequena Introdução às Obras de Gil Vicente, (Lisboa: Progresso, s. a.), p. 129.

${ }_{4}$ Paul Teyssier, Gil Vicente: o Autor e a Obra (Lisboa: Instituto de Cultura e Lingua Portuguesa, 1982), p. 71 y 72.

${ }^{5}$ M. Higino Vieira, "Crítica Social de Gil Vicente, através da Farsa Quem Tem Farelos? «, Portucale, 1941, Vol. XIV, No. 79, p. 27.

'Hope Hamilton-Faria, The Farces of Gil Vicente: A Study in the Stylistics of Satire (Madrid: Playor, 1976), p. 128.

'Con este propósito es sugestivo que "the play has been known [also by] other titles: Farsa dos Eseudeiros or Farsa do Escudeiro Pobre, tities which are very closely connected with the plot « (Jack Horace Parker, Gil Vicente, New York, Twayne, 1967, p. 74). 
entre Isabel y su Madre? Por no percibirse una relevancia esencial de esta escena para el desarrollo de la acción dramática "central «, se concluye que hay en aquélla un problema distinto, independiente del anterior, y que Quem Tem Farelos? es, por esto, una obra de técnica dramática defectuosa que dispara su sátira a dos blancos que no están relacionados lógicamente por ningún evidente nexo interior. Como consecuencia directa de esta concepción "defectuosa", se destaca también el hecho de que el propósito satírico no está realizado en forma de una acción dramática completa, con su principio y fin, ni en los episodios del escudero ni en los de Isabel y su madre: "Quem Tem Farelos?", dice sucinta y categóricamente un crítico, "não encerra um tema abordado de modo completo «. ${ }^{8}$ Es también sugestivo que a algunos críticos parezca que la escena del altercado entre Isabel y su madre responde únicamente a ciertos requisitos de las farsas de golpe y porrazo: "To add to the farcical confusion out comes Isabel's mother to drive the suitor away and scold her daughter « [subrayado nuestro]. ${ }^{9}$

También nosotros creemos que la sátira del escudero ocupa un puesto central en Quem Tem Farelos? Sin embargo, también opinamos que el escuciero desempeña, simultáneamente, otras funciones importantes y que en el contexto dramático total de la obra la sátira de ésta ridícula figura puede considerarse en cierto sentido incluso subordinada a otras intenciones satíricas. A base de esta convicción, en las páginas siguientes mostramos cómo todos los núcleos episódicos de Quem Tem Farelos? se relacionan de modo lógico y armonioso, constituyendo una acción única y completa que se subordina a un tema fundamental, a una visión crítica de un grave problema social y humano.

Después de ahuyentar al ridículo Aires Rosado, quien vino a dar una serenata a Isabel, la madre de ésta reprocha enfurecida y amenazadora:

Isabel, tu fazes isto?

Tudo isto sai de ti!

Isabel, guar-te de mi

que tu tens a culpa disto (p. 77). ${ }^{10}$

Isabel contesta atrevida e impenitente:

Pois si! Eu o fui chamar?

...

Algun demo valho eu?

E algum demo merceço?

$\mathrm{E}$ algum demo pareço,

pois que cantam polo meu? etc. (pp. 77-78).

Esta y otras contestaciones parecidas a su madre le han valido a Isabel severas reprimendas, desde un punto de vista moral, por parte de los críticos. No hay duda, la joven se porta de modo muy sinsolente, com a autora de seus dias «" ¿Qué motivos posibles tendrá para tal conducta? Algunos críticos

${ }^{8}$ M. Higino Vieira, "Crítica Social de Gil Vicente, através da Farsa Quem Tem Farelos?," Portucale, 1941, Vol. XIV, No. 79, p. 27.

'Jack Horace Parker, Gil Vicente, p. 74.

${ }_{10}$ Nos servimos de la edición de Maria de Lourdes Saraiva en Gil Vicente: Sátiras Sociais (Europa-América: 1975).

"M. Higino Vieira, "Crítica Social de Gil Vicente, através da Farsa Quem Tem Farelos?," Portucale, 1940, vol. XIII, No. 76-77, p. 151. 
la explican a base de un "confronto de gerações «12. Hay ciertos aspectos de la disputa que pueden explicarse así, sin duda, pero creemos que sus causas fundamentales trascienden las meras diferencias de generación. Prestemos atención a los reproches que Isabel, a su vez, hace a su madre y que no son, en nuestro juicio, sólo un eco cómico de la arenga que la madre hizo a Aires Rosado, al encontrarlo debajo de la ventana de la hija, según a veces se piensa: ${ }^{13}$

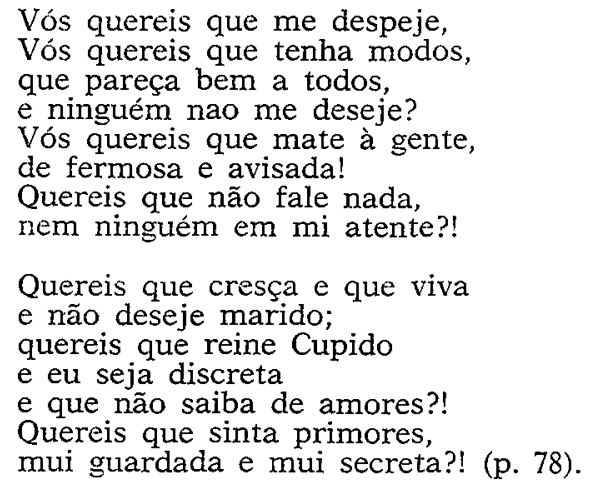

¡Qué deslumbre a todos los hombres con su hermosura! ¿Que impresione con sus "modos « y sagacidad »pareça bem«, que se haga irresistible para todo el que la mire...! Sin embargo, ¡qué sea esquiva con todos! ¡Qué no entre en conversación con nadie! ¡Qué se guarde bien de dejar entrar el sentimiento amoroso en su corazón! ¡Y que no se le ocurra el deseo de tener marido! Estas reglas de comportamiento que la madre impone a la hija no son contradictorias; conjuntamente revelan, con toda claridad, una despótica determinación de controlar y manipular la vida de la hija en todos los sentidos. En realidad, no se opone a un posible amor y matrimonio de su hija, itodo lo contrario!, sino tan sólo a la posibilidad de que estos sucesos ocurran en circunstancias no predeterminadas totalmente por ella misma. De allí que anime a la hija a ostentar su belleza en público, como yesca para un marido conveniente, pero que, a la vez, le prohiba cualquier iniciativa propia. Las inclinaciones personales y los sentimientos íntimos de la hija no cuentan en absoluto, en cuanto no coincidan con los planes de la madre. Esta piensa que aquélla no debe empeñarse en "casar a plazer" y que es suficiente que el marido "tenha o que houver mister", como se dice en Inês Pereira, en situación análoga. ${ }^{14}$

En cierto momento la madre le reprocha a Isabel: »tens tão má criança« (p. 77), pero es muy importante observar que por "criança" ella entiende, además de una sumisión completa, sólo los »modos« exteriores de ser. Obviamente, para encontrar marido, no considera esencial la virtud en su hija. A ésta quiere casarla (mejor diriamos: venderla) sólo a base de su belleza física, desentendiéndose por completo de todos sus demás valores y - lo que

${ }^{12}$ M. de Lourdes Saraiva, Gil Vicente: Sátiras Sociais, nota en la p. 79.

${ }^{13}$ Thomas R. Hart, Gil Vicente: Farces and Festival Plays (Eugene: University of Oregon, 1972, p. 30.

14 Véase nuestro estudio: "Inês Pereira - La imperfecta casada« en Estudios sobre el teatro de Gil Vicente: Obras de tema amoroso, BBMP, 1983, pp. 54-70. 
es aún más importante para comprender la conducta subsecuente de Isabel de sus preferencias sentimentales, de sus inclinaciones naturales, de su dignidad personal.

Contra esta total y humillante supresión de su libertad, individualidad y naturaleza y contra la hipocresía de su madre protesta con tanta vehemencia Isabel en los versos citados arriba. En otros momentos la protesta es aún más atrevida, acerba y desafiante:

Velha: Qué dirá a vizinhança?

Dize, má mulher sem siso!

Isabel: Que tenho eu de ver com isso? (p. 77).

Velha: Não deprendeste tu assi o verbo de Anima Christi, que tantas vezes ouviste!

Isabel: Isso não é para mi! (p. 79).

Isabel infiere claramente que a ella no le importan sólo las apariencias de conducta virtuosa y religiosa, jcomo a su madre.! Nótese el fuerte acento en el eu, mi que invita evidentemente al contraste con tu, ti.

"E pois qué [es para ti] ? «, continúa preguntando la madre, e Isabel contesta acalorada:

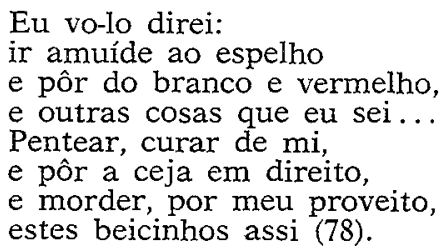

Estas declaraciones se han interpretado siempre en el sentido más literal, como deseos efectivos de Isabel. ¿No se percibe el tono irónico con que las expresa? ¿No se comprende su propósito de respuestas sarcásticas a las imposiciones específicas de su madre?

No quiere quizás la madre que su hija »mate à gente« con su belleza física? Si así es, dice Isabel, quiere satisfacer a su madre por completo: extremará el cuidado de su apariencia en todos los pormenores. Pasará mucho tiempo ante el espejo, recurrirá a todos los afeites disponibles - ¿no tienen quizás estos la virtud de encubrir toda imperfección? -, no evitará ningún medio artifical para crear una ilusión cuanto más eficaz de belleza...

Considerada la preocupación ce la madre con la belleza física de la hija, como único caudal importante para conseguir un marido, ¿no es muy imprudente e improcedente, pregunta ésta, con malicia, implícitamente, mandarle que labre, file y teja:

$$
\begin{aligned}
& \text { Isabel: Faz [o lavrar] a moça mui mal feita } \\
& \text { Corcovada, contrafeita, } \\
& \text { de feiçao de meio anel! } \\
& \text { E faz muito mau carão } \\
& \text { e mau costume de olhar, etc. (p. } 80) .^{15}
\end{aligned}
$$

${ }_{15}$ En La perfecta casada Fray Luis de León recomienda: "ninguna cosa hay que las haga preciar [a las mujeres] como el asistir en ella [en la casa] a su oficio... hilando y tejiendo y teniendo cuenta con su rincón« ( Obras completas 
Además de perjudicar su belleza física, estos trabajos domésticos ¿no deslustrán quizás también su categoría social, con que la madre de seguro désea también presentarla a los pretendientes?

Isabel: Eu sou filha de moleiro?

Em roca me falais vós?

-.

Achais outro mais honrado

oficio para eu saber? (p. 80).

No son estos trabajos domésticos, pues, sino los "modos«, además de la belleza física, lo que de veras importa en la búsqueda de un marido:

\author{
Ensinar-me a passear \\ para quando for cassada \\ ... \\ Saber sentir um recado \\ e responder improviso, \\ e saber fingir um riso \\ falso e bem dissimulado! (p. 79).
}

Aprender a pasearse con afectación, a flirtear con artimañas, a prodigar sonrisas hipócritas, a ser infiel sin escrúpulos... "para quando for cassada". Particularmente estas últimas declaraciones citan los críticos para destacar la frivolidad y la inmoralidad de Isabel: "A corrupção dos costumes é evidente: estos risos falsos e dissimulados, que Isabel ensaiava, são um excelente tirocinio para as infidelidades conjugais ... Nem outra atitude era de esperar duma donzela que, con estas frioleiras se preparava para o casamento. ${ }^{16}$ "[Isabel representa a la mujer] who is wholly uninterested in questions of morality. " ${ }^{17}$ Como en los ejemplos anteriores, tales opiniones hacen caso omiso de la ironía y el sarcasmo con que Isabel dice todo esto. ${ }^{18}$ Sin embargo, si la ironía y el sarcasmo no se notan tan fácilmente en los versos ya citados, ¿es posible no percibirlos en las últimas "promesas« que Isabel hace a su madre?

mãe, deixai-me vós a mim:

vereis como me atavio! (p. 81).

¡Que no se preocupe su madre, porque ella va a satisfacerla por completo: va a hacerse irresistiblemente vendible con su apariencia! Con el fuerte acento en vos, vereis, Isabel hace comprender inconfundiblemente su insinuación de que esos proyectos de »perfeccionar« su belleza y sus "modos« no tienen nada que ver con sus propios deseos y conceptos de lo que representa la verdadera belleza y los buenos modos de conducta.

castellanas, ed. F. García Madrid, B. A. C., 1959, p. 325). Estas actividades eran parte de la conducta de una mujer virtuosa en el siglo XVI. Sin embargo, por todo lo que hemos ya visto, es obvio que la madre de Isabel quiere que esta se ocupe en estas actividades, ante todo, para crear la apariencia de virtud en la opinión de la gente. Veáse nuestro estudio sobre Inés Pereira, citado en la nota anterior.

${ }_{16}$ M. Higino Vieira, "Crítica Social de Gil Vicente, através da Farsa Quem Tem Farelos'« Portucale, 1940, Vol. XIII, No. 76-77, p. 150.

${ }_{17}$ R. Hart, Gil Vicente: Farces and Festival Plays, p. 34.

${ }^{18}$ El lector imagina que en su réplica a la madre, a partir de "Eu vo-lo-direi«, Isabel imita, con intenciones burlescas, sher mother's gestures and intonation", como sugiere T. Hart (Gil Vicente: Farces and Festival Plays, p. 29). 
Por fin, no debemos pasar por alto tampoco otra declaración de Isabel, en que su ironía y sarcasmo nos parecen aun más evidentes, por ser tan hirientes: Al describir los "modos" que va a aprender, para ser como su madre quiere que sea, Isabel añade:

não digam que fui criada

en cima de algum tear! (p. 79).

La malicia se hace obvia al recordar el lector que Isabel nunca se preocupó de lo que la gente pudiera decir, según su propia afirmación: »Que tenho eu de ver com isso? « (p. 79). La que se preocupa del »qué dirán (»Que dirá a vizinhança?«, p. 79), es únicamente su madre. De paso observemos que las muchas invectivas coléricas con que la madre cubre a Aires Rosado no responden únicamente al cieleite del autor en su poder inventivo en el dominio del lenguaje vituperativo, ${ }^{19}$ sino, con toda probabilidad, también al propósito de destacar la preocupación ridícula de aquella "velha rabujenta e meia bruxa $\ll^{20}$ de demostrar a toda la "vizinhança" su ardor en defensa del honor de su casa ${ }^{21}$. Sólo en este sentido tiene el muy extenso pasaje de las invectivas plena función dramática según nosotros.

Es de importancia crucial tener en cuenta la disposición de Isabel que hemos destacado arriba también para explicar su cita con Aires Rosado. Nótese, ante todo, el hecho importante de que éste no le gusta en absoluto a la joven. Lo dice categórica y gráficamente:

Trama a quem o deseja nem espera desejar! (p. 77).

Como se ve, a Isabel le parece inconcebible que cualquier mujer pueda desear a este hombre insubstancial. Durante la cita misma se hace obvio por las reacciones de Aires Rosado (»Oh! Que vós faço eu aqui?; Que são?... Rebolarias?; E mais, ride-vos de mi?; Eu, que difamo de vós: Yá tornais ao difamar?«, etc., p. 67, 68 y 70) que Isabel lo desprecia en todos los sentidos y que todo ese derroche de declaraciones amorosas la deja por completo fría e indiferente. Esto último se reafirma, con rasgo cómico genial, en la revelación de Isabel de que al escuchar la "gran recuesta " de Aires Rosado se le quedó »um pé dormente« (p. 69). ¡La sangre no hierve por las venas de Isabel al escuchar a Aires Rosado!

Se podría quizás pensar que Isabel escucha tanto tiempo las declaraciones amorosas de Aires Rosado, porque, a pesar de considerarle despreciable, éste representa, en un sentido simbólico, su único contacto directo, libre, con el mundo exterior y con el amor, lo cual pondría aun más de relieve su deses-

${ }^{19}$ H. Hamilton-Faría, The Farces of Gil Vicente, p. 129: "The invectives heaped upon Aires Rosado save this farce from being rated among the least creative and expressive of the vicentine comedies." Veáse el muy interesante análisis de estas invectivas en Paul Teyssier, La Langue de Gil Vicente (Paris: 1959), pp. 504-506.

${ }^{20}$ Higino Vieira, "Crítica Social de Gil Vicente, através da Farsa Quem Tem Farelos?«, Portucale, 1940, Vol. XIII, No. 78, p. 200. La madre de Isabel revela un gran parecido, en varios aspectos, con Bernarda Alba.

${ }^{21}$ Higino Vieira, observa bien que la madre reprende a la hija sólo "para salvar as aparências e dar satisfaçâo à opiniâo pública" (Portucale, 1940, Vol. XIII, No. 78 , p. 202). 
perada situación. ${ }^{22}$ Esta posible explicación se armoniza con otra que, a su vez, coincide y refuerza considerablemente nuestra interpretación de la actitud sarcástica e irónica de Isabel como factor decisivo para comprender la lógica de todas las situaciones en la obra.

Comentando el pedido que Aires Rosado hace a Isabel: »Ide ver se está acordada [la madre] (p. 72), M. de Lourdes Saraiva dice; »O Escudeiro pede a Isabel que vá ver se a mãe dorme, apenas para ficar mais à vontade; mas Isabel não percebe e diz à Mãe que o Escudeiro lhe pretende falar «. ${ }^{23}$ Nos parece muy perspicaz la observación de que la madre no sorprende a su hija y a Aires Rosado en la cita, como piensan otros críticos, pero, por desgracia, no coincidimos con la conocida estudiosa en que Isabel despierta a su madre por mera simpleza mental. Creemos más bien que lo hace de modo por completo deliberado y con complacencia perversa. Su mayor deseo es precisamente que su madre la encuentre con Aires Rosado, porque tal suceso, visto desde su ánimo frustrado y rencoroso, representa la venganza más apropiada. ¿No le ha enseñado su madre a vivir y a conseguir marido a base de puras apariencias exteriores? ¿No le ha hecho quizás comprender harto bien que los valores genuinos, internos de la persona son irrelevantes? Con hiriente sarcasmo, Isabel se proyecta como discípula excelente, haciendo ver a su madre el resultado concreto de esas enseñanzas: su cita con Aires Rosado, a quien todo el mundo conoce como individuo sin substancia alguna; quien vive de meras apariencias ridículas y quien se afana en engañar a todo el mundo con ellas. ${ }^{24}$ La madre se lanza contra el escudero:

Que não fartas de pão

e queres musiquiar, etc. (p. 76),

con lo cual Isabel tiene la certeza de haber realizado su propósito, pero, claro está, no enteramente, pues, ¿no sería quizás por completo inconcebible que

${ }^{22}$ En toda esta escena no se oye nunca la voz de Isabel, quien escucha a Aires desde la ventana de su cuarto. T. R. Hart comenta este hecho así: "This is, of course, wholly unrealistic: since he [Aires Rosado] obviously hears what she has to say, there is no very good reason why we should not hear it, too (Gil Vicente: Farces and Festival Plays, Preface, p. 29). Podría arguirse que con este procedimiento se nos ofrece, en efecto, una visión más realista de la situación, pues la voz de Isabel, en el cuarto. no puede ser audible como la de Areis Rosado, en la calle. Sin embargo, creemos que Gil Vicente tuvo otros motivos para eilo: la figura de Isabel encubierta por la oscuridad del cuarto, su voz que el público no puede oír en absoluto simbolizan, de modo muy sugestivo, su situación de mujer oprimida. Uno de los más extraordinarios efectos dramáticos de esta obra consistirá precisamente en el contraste que después se producirá entre esta pasividad de Isabel que se nos hace percibir de modo tan interesante y la explosión volcánica de su réplica a la madre, con que »desagrava os seus direitos« (Joaquim Leitâo, "A Mulher na obra de Gil Vicente«, en Gil Vicente: Vida e Obra, Academia das Ciências de Lisboa, 1939 , p. 436). Isabel puede compararse, en varios aspectos, con las hijas de Bernarda Alba. Varios críticos (Hart, Vieira) han sugerido una semejanza entre Isabel e Inês Pereira y Constança del Auto da India. El paralelo con Inês nos parece justificado hasta cierto punto; con Constança, no en absoluto. Véanse nuestros estudios sobre Inês Pereira y el Auto da India en Estudios sobre el teatro de Gil Vicente - Obras de tema amoroso, BBMP, 1983.

${ }^{23}$ Sátiras Sociais, nota en la p. 72.

${ }^{24} \mathrm{El}$ hecho de que Isabel rechace toda responsabilidad por la presencia de Aires Rosado debajo de su ventana (»Pois si! Eu o fui chamar?«, p. 77) no contradice nuestra sugerencia. 
su madre comprendiera, con toda claridad, hasta qué punto se asemeja ella misma al engañoso escudero que reprende con tanta cólera?

Quem Tem Farelos? se concluye con este diálogo:

Isabel: Isso vai sendo de día: eu quero, mãe, almoçar

Velha: Eu te farei amassar...

Isabel: Essa é outra fantasia! (p. 81).

Este modo brusco de acabarse la obra suele perturbar a los críticos, pues añoran una "verdadera« conclusión de las acciones dramatizadas: " $\mathrm{E}$ assim, ante o nosso pasmo, porque não esperávamos tam súbito corte fenece este primeiro tenteio de sátira social entre nos «. ${ }^{25}$ Por la misma razón, en parte, se opina también que Quem Tem Farelos? "não é obra do pensador que profunda o âmago dos acontecimientos « ${ }^{26}$ ¡Qué ironía! ¿No se dramatiza qui zás de modo genuinamente genial la única conclusión verosímil de la situación anteriormente presentada? Por las peculiares actitudes que la madre y la hija han adoptado frente a la vida, por las razones que hemos visto, sus futuras relaciones estarán de seguro henchidas de hostilidad y rencores. Es este lóbrego futuro lo que se preanuncia, con recurso dramático tan extraordinario, al fin de la obra.

$$
* * *
$$

Refiriéndose a los personajes de las farsas gilvicentinas, entre los cuales se encuentran esos notorios »hinchados " hidalgos y escuderos, Menéndez Pelayo afirma que shay que llegar hasta El Lazarillo de Tormes para encontrar creaciones semejantes «.27 A partir de esta observación del ilustre polígrafo, los editores y críticos de esta famosa novelita (1554) suelen recordarnos a veces que los hidalgos y escuderos gilvicentinos (Farsa de Inês Pereira, $O$ Juiz da Beira, Quem Tem Farelos?, Farsa dos Almocreves, etc.) representan antecedentes interesantes del famoso escudero de Lazarillo de Tormes:

En fin on n'a pas assez pris garde que le Tratado $I I I$, celui de l'»escudero«, consideré à juste titre comme la partie proprement géniale du Lazarillo, a lui-même des assises folkloriques et littéraires, sans lesquelles l'auteur n'aurait peut-être pas songé à le bâtir... déjà le thèâtre de Gil Vicente, entre 1515 et 1530, nous montre l'escudero porté sur la scène au Portugal comme un personnage de farce parfaitement dessiné, sinon stéréotypé, avec des traits qui annoncent étrangement ceux du maître de Lazare. ${ }^{28}$

Bataillon y otros estudiosos destacan algunas analogías importantes, ${ }^{29}$ pero de un modo más bien fugaz, y dejan sin señalar varias otras que a nosotros parecen muy significativas. Así, principalmente en consideración de la gran

${ }_{25}$ M. Higino Vieira, "Critica Social de Gil Vicente, através da Farsa Quem Tem Farelos?, Portucale 1940, Vol. XIII, No. 74-75, p. 92; 1941, Vol. XIV, No. 79, p. 27. ${ }^{26}$ Ibid.

${ }^{27}$ Marcelino Menéndez Pelayo, "Gil Vicente«, en Obras Completas de $M$. Menéndez Pelayo (Santander: Aldus, 1944), Vol. XIX, pp. 380-381.

${ }_{28}$ Marcel Bataillon, Introduction (pp. 27-28) a la traducción del Lazarillo de A. Morel-Fatio, La Vie de Lazarillo de Tormes (Paris: Ambier, Editions Montaigne, 1958).

${ }_{29}$ M. Battaillon, Ibid.; Angel Valbuena Prat, La novela picaresca española (Madrid: Aguilar, 1946), p. 34; Francisco Rico, Lazarillo de Tormes (Barcelona: Planeta, 1976), pp. XXXIII-XXXV. 
importancia que implica el problema de las fuentes de Lazarillo de Tormes, según lo comprueban los ya numerosos estudios escritos sobre ellas, intentaremos un cotejo más detenido que los anteriores de los personajes gilvicentinos - amos y criados - de Quem Tem Farelos? con el escudero y su criado de la genial novelita española.

Al encontrarse en la calle Ordonho y Apariço, "moços de esporas", éste contesta al saludo de aquél ( Cómo te va compañero?») de un modo muy malhumorado:

Se eu moro com um escudeiro,

como me pode a mi ir bem? (p. 54).

Apariço elabora su contestación, destacando en gráficos detalles la extrema pobreza de su amo:

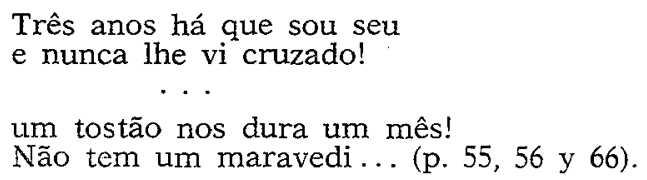

A Ordonho no le sorprende en absoluto esta revelación, pues, su propio amo, también escudero, padece igual miseria:

Que, aun que le quieran hurtar,

no ha hi de qué sisar

ni el triste no lo tien!

y quanto el cuytado lleva

todo lo lleva alquilado (p. 61 y 60 ).

El lector evoca "la bolsilla« del escudero que Lazarillo halla, „sin maldita la blanca, ni señal que la hobiese tenido mucho tiempo« (p. 54) (10 $^{30}$ el »real« que un día, no se sabe por »cuál dicha o ventura« extraordinaria, sentró en el pobre poder « de su amo (p. 56), como también la casa desolada y vacía de éste, en que Lazarillo no encuentra "ni tajo, ni banco, ni mesa", sino tan sólo »paredes«, aunque su amo se preocupe mucho en »tener cerrada la puerta con llave« (p. 44). Claro está, la casa y aun la »negra dura cama« (p. 50), en la que el escudero duerme, están alquiladas.

En efecto, tan grande es la pobreza del amo, lamenta Apariço, que:

Morremos ambos de fome não comemos quase nada (p. 59 y 56).

Lazarillo llora su »cercana muerte venidera«, (p. 45) porque, por idénticas razones, él y su amo no comen nada o »casi nada« (p. 47).

"Nem de pão nos fartamos« (p. 56), continúa lamentándose Apariço. Cuando, por algún milagro, entra algún pedazo de pan en la casa, su amo, por completo olvidado de cualquier decoro social y cediendo a la terrible hambre que lo aqueja, lo agarra:

e chanta nele bocado

como cão! (p. 57).

30 Citamos por la edición de Lazarillo de Tormes de Francisco Rico: (Veáse nota anterior). Indicamos la página en paréntesis tras la cita. 
¡Quién no recuerda la escena en que el escudero comienza »a dar fieros bocados« (p. 46) en el pedazo de pan y otra en que roye "mejor que un galgo" (p. 53) la uña de vaca que le ha traido el compasivo Lazarillo! Este comparte con su desvalido amo lo que consigue en la calle, encomendándose »a las buenas gentes" (p. 51). Aunque no hay ninguna referencia explícita a ello, parece que en Quem Tem Farelos? ocurre algo semejante. ¿De qué otro modo entran esos ocasionales "pedaços de pão" en la casa del escudero? (Recuérdese la observación de Apariço: "Não tem um maravedi... ele não tem que me dar, nem ele tem que the eu dê«, p. 57 y 66). Considerando »la negra que llaman honra" (p. 50), que lo inhibe del mismo modo que al amo de Lazarillo, sería inconcebible que el de Apariço trajese "pedacos de pão" de la calle, por la caridad de »las buenas gentes « ${ }^{31}$ De hecho, en la calle se afana en proclamar a todos los vientos no sólo su suficiencia, sino su abundancia respecto a la comida. En la comiquísima escena de la serenata manda a su mozo que acalle a los perros, que lo han interrumpido con sus aullidos, hartándolos de pan:

Ou, vai, da-lhes senhos paes!

farta-os, eramá, de pão (p. 65 y 68).

Como el escudero mismo está hambriento en extremo por falta absoluta de cualquier clase de comida en su casa (ironiza Apariço: »E ele não tem meio pão«, p. 65), su orden corresponde perfectamente, en intención, a la aparición del amo de Lazarillo a la puerta de la casa, »escarbando « con la paja »los que nada entre sí tenían (p. 56) para convencer a todos que ha almorzado bien. Frente a su propio criado, cuando más hambriento está, afecta suficiencia y bienestar, asimismo como el amo de Lazarillo:

Vem tão ledo! Sus! Cear!

Como se tivesse quê! (p. 57).

Creemos que nuestras sugerencias de que en Quem Tem Farelos? el criado mantiene al amo limosneando encuentra respaldo en la muy significativa escena inicial, en que los dos mozos, Apariço y Ordonho, piden por las calles salvado para el caballo y la mula de sus amos: "Quem tem farelos?" (p. 53). M. de Lourdes Saraiva comenta, »O auto revela que seria costume a compra pela ruas, com pregão do género « ${ }^{32}$ Sin embargo, recordando siempre que los amos no tienen dinero en absoluto (Apariço declara no haber visto ni un cruzado en la posesión de su amo en "três anos«, en el preciso momento en que está pidiendo salvado, p. 55), ¿con qué comprarían los criados lo que buscan? Nótese el hecho significativo de que nadie contesta a sus pedidos:

Ordonho: Quiérome ir a la posada?

Apariço: $\mathrm{E}$ os farelos?

Ordonho: Paja sola! (pp. 61-62).

${ }^{31}$ El amo de Ordonho se sustenta, en parte, alquilando la »mula seca como un palo!« (p. 51) que tiene.

${ }^{32}$ Gil Vicente: Sátiras Sociais, nota en la p. 53. 
Siendo del todo inverosímil que en el pueblo no hubiera salvado para vender, ¿no es quizás justificado pensar que »las buenas gentes « están ya hartas de abastecer salvado, por caridad, a los animales de los presuntuosos y parasíticos escuderos? En el contexto de toda la situación en la obra, el Quem tem farelos? « de Apariço - primera línea del texto - revela de modo muy sugestivo la abnormalidad e ironía de toda la relación entre amo y criado. Creemos que sólo por no haberse percibido la importante función dramática de la busqueda del salvado por parte de los criados, en el sentido sugerido arriba, se pudo criticarle injustamente al autor de haber creado una escena dramáticamente inconsecuente: »Na Farsa Quem Tem Farelos? há inverossimilhanças. Ordonho e Apariço vêm a buscar farelos não se sabe aonde... e afinal esquecem-se de comprar os farelos, intuito principal a que vieram. ${ }^{33}$

Entre los momentos más divertidos y reveladores de la psicología y la estrategia engañosa del escudero se encuentran las racionalizaciones de que éste se sirve, simulando una postura de profunda sabiduría salomónica, para explicar a Lazarillo cuán preferible es que no coman:

Señor, mozo soy que no me fatigo mucho por comer... Virtud es ésa - dijo él... Porque el hartar es de los puercos, y el comer regaladamente es de los hombres de bien... vivirás más y más sano... Porque no hay tal cosa en el mundo para vivir mucho que comer poco (p. 45 y 47).

Descontadas ciertas importantes diferencias de actitud y tono en las relaciones entre amo y criado en las dos obras (se debe destacar especialmente que la cordialidad, el afecto y la compasión están totalmente ausentes en la pareja gilvicentina), en Quem Tem Farelos? hay una escena, en particular, que nos resulta sugestivamente parecida a la de Lazarillo de Tormes presentada arriba:

Aires Rosado: Apariço, bem sei eu

que te faz mal tanto viço.

Apariço [aparte]: $\mathrm{E}$ desde ontem, não comemos!

Aires Rosado: Vilão farto, pé dormente (p. 64).

Para calmar a Lazarillo y, ante todo, para no tener que revelarle su extrema indigencia, su amo recurre a menudo a promesas de una inminente satisfacción y prosperidad para ambos: »después cenaremos; más agora hacerlo hemos de otra manera; presto nos veremos sin necesidad; en esta desastrada [casa] no hemos de estar más de en cumpliendo el mes, " etc. (p. 45, 47, 52, 56). Para poder retener a Apariço en su servicio, Aires Rosado asimismo le hace continuas y aun más extravagantes promesas (aunque, claro está, las del amo de Lazarillo no son en absoluto más fáciles de realizar):

Apariço: Diz que m'ha de dar a El Rei

e tanto »farei, farei«... (op. 58).

Además de las continuas promesas que le hace su amo, Apariço parece tener otra razón para quedarse con él. Cuando Ordonho se extraña de que

${ }_{33}$ M. Higino Vieira, "Crítica Social de Gil Vicente, através da Farsa Quern Tem Farelos?« Portucale 1941, Vol. XIV, No. 79, pp. 27 and 28. 
a pesar de las muchas deprivaciones Apariço siga al servicio de Aires Rosado (»Y pues porqué estás con él?«, p. 58) recibe esta contestación:

\section{Apariço: Bofá! Não sei qual me tome! \\ Sou já tão farto de fome \\ como outros de comer (p. 59).}

En cuanto estos versos se interpreten como una reflexión escéptica sobre la posibilidad de encontrar un amo dispuesto a tratarle bien, las consideraciones fatalistas de Lazarillo, al ocurrirsele la idea de dejar a su segundo amo (según las recuerda cuando sirve al escudero), son sugestivamente parecidas a las de Apariço: "allí se me vino a la memoria la consideración que hacía cuando me pensaba ir del clérigo, diciendo que aunque aquél era desventurado y mísero, por ventura toparía con otro peor« (p. 45). ${ }^{34}$

A pesar de la »afligida y hambrienta persecución« (p. 56) que padece, el amo de Lazarillo se pavonea por las calles, en nombre de la "negra que llaman honra«, pretendiendo gran holgura económica:

¿Quién encontrará a açuel mi señor que no piense, según el contento de si lleva, haber anoche bien cenado y dormido en buena cama $y$, aun agora es de mañana, no le cuenten por muy bien almorzado?... ¿A quién no engañará aquella buena disposición y razonable capa y sayo? ¿Y quién pensara que aquel gentil hombre se pasó ayer todo el día sin comer con aquel mendrugo de pan que su criado Lázaro trujo? (p. 49).

Este ademán ridículo que el escudero siempre exhibe en público para poder sostener la mentira de su bienestar e importancia personal ¿no está quizás también plenamente prefigurado en los siguientes pasajes de Quem Tem Farelos? en que los criados se mofan de "la patética vanidad de sus amos?"

Apariço: Não comemos quase nada eu, o cavalo nem ele.

E se o visses brasonar

e fingir mais de esforçado!

E todo o dia aturado se lhe vai em se gabar!

Não sei como se mantém

que não está debilitado

que não comeu hoje bocado! ${ }^{35}$

Ordonho: Sueñase muy gran señor

y no tiene media blanca! (p. 56, 57, 59).

No tienen ni »media blanca《 estos individuos (aun los míseros efectos personales que tienen "todo lo llevan alquilado«) y no obstante alardean de poseer riquezas inauditas:

${ }^{34}$ De la relación entre lazerar, lazeria, y Lazaro, nombre que el autor anónimo escogió para el protagonista de la famosa novela se han expresado ya muchas opiniones. Sin embargo, consideramos oportuno señalar que en Quem Tem Farelos? Apariço, criado del escudero, se identifica con su mucha lazeira:

Morremos ambos de fome

e de lazeira todo o ano! (p. 54).

${ }^{35}$ M. de Lourdes Saraiva: „Aires Rosado: os nomes dos personagens de Gil Vicente são, geralmente, significativos do carácter respectivo. Neste caso: ares (aparéncias) rosadas« (Gil Vicente: Sátiras Sociais, nota en la p. 62). 
Aires Rosado: tenho mais tapeçaria

cavalos na estrebaria

que não há na Corte tais! (p. 72).

Creemos que se deben sobreentender alardes parecidos por parte del escudero de Lazarillo de Tormes, además de tener en cuenta su presuntuoso y engañoso ademán de bienestar con que se ostenta en público, cuando oímos que la vieja que viene a cobrar el alquiler pregunta a Lazarillo: " ¿Qué es de la hacienda de tu amo, sus arcas y paños de pared y alhajas de casa?" (p. 64). A Lazarillo mismo el escudero declara: "No soy tan pobre que no tengo en mi tierra un solar de casas... que valdrían más de dosciento mil maravedís... un palomar... y otras cosas « (p. 61).

De igual modo como el amo de Lazarillo, quien a pesar de todas sus patéticas deficiencias personales se proclama igual a los más »altos«, »de el rey abajo (p. 60,61) y quien se queja de los »señores de título " que no lo aprecian ni reconocen sus extraordinarias habilidades (a todos los amos potenciales desprecia y denigra: "gente tan limitada", etc., p. 62), Aires Rosado alardea de su »insigne« abolengo que le otorga el privilegio - ¡la él sólo! - de un trato íntimo con el rey y que, simultáneamente, justifica su actitud de altivez hacia los demás:

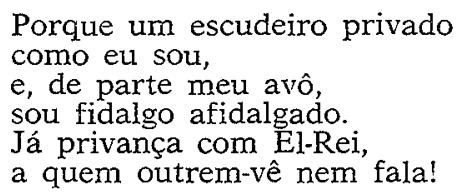

Apariço [aparte]: Deitam-no fora da sala (p. 71).

Hablando de su propio amo, pero con total aplicabilidad también al de Apariço, Ordonho observa:

Y, sobre ser el peor,

burla de buenos y malos! (p. 61).

El misterio con que el escudero envuelve sus andanzas, en gran parte, sin duda, para encubrir la verdad acerca de su miserable condición ("no sé yo cómo o dónde andava y qué comía, « dice Lazarillo, p. 55) tiene su contraparte en el secreto que mantiene Aires Rosado respecto a sus quehaceres cotidianos, incluso con su propio criado:

Ordonho: Con quién vive? [¿A quién sirve?]

Apariço: Que sei eu? (p. 54).

Cuando el escudero no está "papando aire por las calles" (p. 53) pasa el tiempo "paseándose por el patio" (p. 51) de su mísera casa, compadeciéndose por su »adversa fortuna« y de seguro también inventando las »dulzuras" - Ni Ovidio escribió tantas, nos informa Lazarillo - que al salir a la calle piensa decir, "hecho un Macías«, a las mujeres dispuestas a oúrlas (p. 50).

En Quem Tem Farelos? Apariço invita a Ordonho a ir con él a divertirse, escuchando "as trovas frías, sem graça, vazias« (p. 55) que su amo 
"passeando pela casa" y "sempre falando so... fez á dama" (p. 55, 62). ${ }^{36}$ Estos interminables paseos de Aires Rosado "pela casa« se deben principalmente al hecho de que durante el día está »sempre encerrado«, porque »anda mal roupado« y »não ousa de se mostrar en público (p. 56). El amo de Lazarillo es indigente en el mismo aspecto, pues »a falta de paño de manos« debe secarse la cara y las manos con la »halda del sayo « (p. 49), pero todavía tiene "razonable capa y sayo" (p. 49) con que salir a la calle sin vergüenza. Cuando éstos ya no sean tan "razonables", ¿cabe quizás dudar en absoluto de que no se atreva a salir, sino cuando »vem alta noite (p. 57), como Aires Rosado, su correligionario en »las cosas de la honra (p. 59)? Con toda probabilidad, se debe a una gran aprehensión por el inminente desgaste de su capa, lo cual lo obligaría a renunciar a sus andanzas diurnas la extrema atención con que la cuida: »Desque fuimos entrados«, narra Lazarillo, "quita [el escudero] de sobre sí su capa y, preguntando si tenía las manos limpias, la sacudimos y doblamos y, muy limpiamente soplando un poyo que allí estaba, la puso en él« (p. 44).

Antes de salir a la calle, comúnmente en busca de alguna "gran recuesta" con alguna mujer, los escuderos de Quem Tem Farelos? se asean de un modo obsesivamente meticuloso. De su amo nos dice Ordonho:

\author{
y presume allá en palacio \\ de andar con damas, el triste! \\ Quando se viste, \\ toma dos horas de espacio (p. 60).
}

Apariço observa iguales prácticas en Aires Rosado:

Pentear e jejuar

todo o día sem comer (p. 55).

Por su parte, Lazarillo observa que antes de salir a la calle, su amo siempre »vístese muy a su placer, de espacio« (p. 48). Una de las cosas que más le llaman la atención ya en el primer encuentro con el escudero es que

${ }^{36}$ M. de Lourdes Saraiva, Sátiras Sociais, p. 63: „Os poemas de Aires Rosado são verdadeiras obras-primas de cabotinismo literario«. María Teresa Rita dice: »A mesma falta de respeito pela verosimilhanca [como en el diálogo entre Aires Rosado e Isabel] se manifiesta no encadeamento de situaciones. Um exemplo: - criado do Escudeiro convida um colega a assistir às »sandices « poeticas do amo; automáticamente, e sem mais preparos, este aparece em cena a ler o seu cancioneiro« (Citado por Hart, Farces and Festival Plays, Preface, pp. 329-30). Leyendo atentamente el texto, se observa que Aparico convida a Ordonho a la casa del amo: "Mas vem comigo a verás« (p. 62). Mientras siguen dialogando se debe imaginar que caminan hacia la casa. El tiempo está muy condensado, claro está, lo cual es un recurso muy socorrido en el teatro. Al decir Apariço a su amigo: „Escuta tu e verás (p. 62) se hace evidente que han llegado al cuarto en que Aires Rosado está leyendo sus poemas. (Apariço sabe muy bien cuales son las actividades de su amo y cuando ocurren). Se podría imaginar todo esto también de otro modo: la primera escena en que Apariço convida a Ordonho a acompañarle ocurre en la calle y la segunda en que Apariço y Ordonho ya están en la casa del amo se representa después de un brevísimo intervalo que sugiere camino ya efectuado. En el teatro de Gil Vicente faltan a menudo las acotaciones escénicas, porque entre otras razones, él mismo era el director de las representaciones en el palacio y así no las necesitaba para disponer las escenas debidamente. Veáse nuestro estudio sobre el Auto da India en Estudios sobre el teatro de Gil Vicente: Obras de tema amoroso, B.B.M.P., 1983, en que discutimos estos problenias técnicos. Véase también la nota 22 de este estudio. 
éste anda por las calles »bien peinado« (p. 42). F. Lázaro Carreter menciona dos ejemplos en la literatura castellana - posteriores a la farsa gilvicentina - en que se alude al peinado del escudero, explicando que se trata de "notas tópicas y constitutivas de la imagen que de él se forjaba la gente. $\aleph^{37}$ Por su parte, M. de Lourdes Saraiva comenta que »o penteado era um indicativo importante da clase social a que se pertencia. A gente da corte usava cabelo copado, isto é, crescido e tufado como copa de árvore; o cabelo curto era própio do povo. ${ }^{38}$ Vista, pues, desde esta perspectiva del siglo XVI, la obsesión de los escuderos de Lazarillo de Tormes y de Quem Tem Farelos? en vestirse y peinarse meticulosamente no puede interpretarse en absoluto como una loable, aunque excesiva, preocupación con el aseo personal, sino tan sólo como un afán patético de deslumbrar a la gente con su "nobleza", por medio de unas muestras externas que no dejan de revelarse como muy ridículas.

Entre las señales de su "nobleza" que los escuderos de Quem Tem Farelos? ostentan, figura tambien su »ánimo valiente«, claro está:

Ordonho: Habla en roncas, picas, dalles, en guerras y desbaratas

Siempre sospira por guerra, y todo su hecho es nada (p. 60).

Como paralelo pertinente evoquemos aquellos momentos en Lazarillo de Tormes, en que el escudero, para dar aun más convincente prueba de su "valerosa persona« (p. 63), exhibe frente a Lazarillo "los aceros tan prestos" de su espada, con la cual se obliga »a cercenar un copo de lana« (p. 48) y con la cual, pretenciosamente ceñida a su costado, "súbese por la calle arriba con tan gentil semblante y continente, que quien no le conociera pensara ser muy cercano pariente al conde de Arcos« (p. 49). A esta ostentación de nobleza y valor sirve de contraste muy irónico la huída cobarde del escudero, cuando aparecen en su casa sus acredores, un hombre y iuna vieja! (p. 63).

A pesar de todas las pretensiones de nobleza y todas las »dulzuras « que los escuderos dicen a las mujeres, éstas no se dejan engañar por las apariencias. De su amo, Aires Rosado, dice Apariço:

\section{Nenhuma negra tripeira não no quer}

Todas querem que lhe dem

e não curam de cantar (pp. 58-59).

De hecho, Isabel, a quien Aires Rosado corteja, se indigna con estas palabras reveladoras:

Trama a quem o deseja

Nem espera desejar (p. 77),

${ }^{37}$ Fernando Lázaro Carreter, Lazarillo de Tormes en la picaresca, (Barcelona: Ariel, 1972), p. 138.

${ }^{38}$ Gil Vicente: Sátiras Sociais, nota en la p. 55. 
y su madre, con mucho menos delicadeza, le echa en cara su hambre que no puede encubrir, por mucho que se empeñe, con su engañosa presunción:

Vai comer, homem coitado,

e dá ao Demo o tanger! (p. 76).

En Lazarillo de Tormes, según recuerda todo lector, las mujeres, con quienes el escudero está en »gran recuesta«, diciéndoles »dulzuras«, lo dejan pronto "para el que era«, sientiéndole »la enfermedad«, es decir, conociéndolo como pobre que no puede brindarles ni un almuerzo, aunque, "hecho un Macías«, muy otra cosa presuma (p. 50).

Al verse despreciado y calumniado por la madre de Isabel (»bargante rascão«, etc, p. 75), quien considera absurda su persecución de la hija, Aires Rosado declara, aparentemente ofendido y acongojado:

Ir-me ei a tierras agenas

a chorar meu pesare (p. 76),

lo cual parece preludiar de modo muy sugestivo el exilio del escudero de Lazarillo de Tormes en Toledo y las lamentaciones de su wadversa fortuna« (p. 63), por haber salido de su tierra para salvaguardar su honra del »desprecio de ciertos compatriotas suyos.

Por fin, es importante notar la dicotomía que se pone muy de relieve entre los alardes de nobleza y honor y la falta completa de moralidad y virtud en Aires Rosado:

Aires Rosado [habla a Isabel]: Que o saiba vosso pai

e vossa mãe: hão de folgar

tenho mais tapeçaria, cavalos...

Apariço: O Jesus! Que mau ladrão!

Quer enganar a coitada! (p. 72).

El amo de Lazarillo nos da amplias pruebas de su ruindad al exponernos, con pervertido orgullo, todas las acciones deshonestas e hipócritas de que él sería capaz, si se encontrara al servicio de algún "señor de título«; al engañar a sus acreedores y también, claro está, al abandonar a la merced de éstos a su compasivo y cariñoso criado. ${ }^{39}$

Como observa F. Rico, "Quem Tem Farelos? nos presenta ya acuñada la pareja célebre del escudero y su criado ${ }^{40}$ Este, especialmente Apariço, revela unas semejanzas sugestivas con Lazarillo, en particular respeto a la situación en que se encuentra con su amo, según ya se ha mostrado en las consideraciones anteriores sobre sus relaciones con Aires Rosado. A continuación señalamos varias otras analogías en la presentación de los dos mozos que nos parecen significativas.

${ }^{39}$ Veáse "El buen hidalgo" en Lazarillo de Tormes en la picaresca, pp. 187 192, en que F. Lázaro Carreter objeta con razón a la idealización del escudero por parte de algunos críticos. Veáse también nuestras consideraciones: "Torres Naharro y la picarescau en El pensamiento satirico y humanístico de Torres Naharro (Santander: 1977), Vol. I, pp. 230-236.

${ }^{40}$ Lazarillo de Tormes, Introducción, p. XXXIII. 
Las revelaciones que Apariço hace de su mísera vida a su compañero constituyen, de hecho, una autobiografía del desvalido. Con este respecto no deja de ser sugestiva la gran frecuencia del pronombre personal en primera persona, fuertemente acentuado, a través de toda su conversación con Ordonho. Este es el interlocutor, pero resulta evidente que también sirve de pretexto conveniente para que Apariço se desahogue con el relato de su »adversa fortuna«. Ordonho tiene, en suma, la misma función esencial que "Vuestra Merced«, destinatario del relato autobiográfico de Lazarillo. ${ }^{41}$ Cabe también preguntar: los diálogos que Lazarillo reproduce en su narración, ¿no son quizás, entre otras cosas, una reminiscencia, un reflejo revelador de la forma dramática original en que se inspiró el autor?42

Respecto a la forma autobiográfica del relato que discutimos, nos parece muy interesante la observación de Lázaro Carreter, según la cual "hay un Lázaro que rezonga y adivina consigo mismo,${ }^{43}$ según se puede apreciar en varios momentos de la famosa novela. Por ejemplo:

Virtud es esa - dijo él [el escudero] ... Porque el hartar es de los puercos, y el comer regaladamente es de los hombres de bien. ¡Bien te he entendido! - dixe yo entre mi! - (p. 45)

Dígote, Lázaro ... que nadie te lo ve hacer [comer] que no le pongas gana, aunque no la tenga.

La muy buena que tu tienes - dixe yo entre mí - te hace parecer la mía hermosa (p. 52).

Considérense ahora los siguientes pasajes de Quem Tem Farelos (entre otros que no consideramos necesario reproducir):

Aires Rosado: Apariço, bem 'sei eu que te faz mal tanto viço.

Apariço [aparte]: E desde ontem não comemos".

Aires Rosado: Vai, da-lhes senhos pães!

Apariço [aparte]: E ele não tem meio pão...

Aires Rosado: Porque um escudeiro privado... Apariço [aparte]: Mas pelado! (p. 71).

Estas reflexiones y reparos irónicos de Apariço, en los apartes, a las declaraciones y acciones estrafalarias de su amo, representan el punto de vista, el íntimo sentir del desvalido. Este mozo rezongador, ¿no preludia ya muy claramente a Lazarillo también en este aspecto fundamental?

Según se puede apreciar por el cotejo que acabamos de hacer (y que no pretende ser exhaustivo), entre la pareja del escudero y su criado de

${ }^{41}$ Claro está, Apariço tiene la misma función respecto a la narración, aunque más breve, de las "lazerías« de Ordonho.

${ }_{42} \mathrm{M}$. Higino Vieira: "A narrativa sôbre os dois hidalgos é exposta pelos respectivos criados e constitui a primeira parte da farsa ...; a accâo ocupa tôda a segunda parte." (»Critica social de Gil Vicente, a través da Farsa Quem Tem Farelos? «, Portucale, 1940, Vol. XIII, No. 76-77, p. 143). Narración y acción son, pues, dos elementos constitutivos ya en Quem Tem Farelos?.

${ }^{4}$ Lazarillo de Tormes en la picaresca, p. 149. 
Quem Tem Farelos? y la de Lazarillo de Tormes hay extraordinarias semejanzas que abarcan tanto las situaciones generales como los episodios particulares en que protagonizan los personajes, sus manifestaciones externas y psíquicas, detalles de dicción, de expresión verbal, técnicas narrativas, diálogos... Tantas significativas coincidencias hay que resulta de veras difícil imaginar la creación del Tratado III de Lazarillo de Tormes totalmente independiente de la farsa gilvicentina. Diríamos así que entre todas aquellas »assises folkloriques et littéraires« aducidas hasta ahora por la crítica, "sans lesquelles l'auteur n'aurait peut-être pas songé a le bâtir [el Lazarillo de Tormes] «,4 Quem Tem Farelos? debiera considerarse, respecto al Tratado III, como la más sugestiva y la más importante. Sin embargo, aceptando como muy probable el conocimiento de Quem Tem Farelos? por parte del autor de la famosa novela española, a pesar de todas las semejanzas constatadas, la originalidad de ésta no quedaría disminuida en absoluto. Ante todo, tanto los escuderos de Quem Tem Farelos? como el de Lazarillo de Tormes son, en esencia, "trasuntos fidelísimos de la vida peninsular ${ }^{45}$ Con esto queremos decir que los respectivos autores, probablemente hombres de ideología y de intención satírica muy parecidas, encontraron la inspiración más importante en la realidad misma, en la existencia cotidiana de esos patéticos individuos. Por otra parte, la imitación de elementos folklóricos y literarios por el autor de Lazarillo de Tormes conlleva siempre una innovación. Este hecho, ya observado por muchos críticos, se comprobaría de un modo muy convincente en un análisis dedicado específicamente a examinar la originalidad del Tratado III respecto a Quem Tem Farelos? Un estudio semejante revelaría, ante todo, la radical originalidad del anónimo autor en el proceso mismo de imitar el modelo. ${ }^{46}$ A Quem Tem Fa-

${ }^{44}$ Veáse nota 28. Apariço:

${ }^{45}$ M. Menéndez Pelayo, Gil Vicente, p. 381. Recordemos una contestación de

Se eu moro com um escudeiro,

como me pode a mi ir bem?

Esta pregunta tan patentemente retórica tiene valor histórico, documental, porque presupone como hecho universalmente conocido y aceptado la insubstancialidad del estado escuderil ya a principios del siglo XVI.

${ }^{46}$ Entre los aspectos más importantes que habria que examinar atentamente figurarían las esporádicas revelaciones del criado que constituyen un punto de vista que en Lazarillo de Tormes se transforma en una visión individual de la vida y en el problema central de la obra; las meras alusiones de los personajes de Quem Tem Farelos? que en Lazarillo de Tormes se recrean en extraordinarias situaciones. Por ejemplo, Ordonho declara que su amo es tan pobre que en su casa »no hay hi de qué sisar«. En Lazarillo de Tormes se produce una escena fascinantemente cómica al presentársenos el escuchero mismo con una pretendida preocupación por los bienes inexistentes de su casa: "Lazaro ... mira por la casa ... y cierra la puerta con llave, no nos hurten algo" (p. 48); cambios en los episodios para matizar los caracteres con rasgos anteriormente inexistentes. Por ejemplo, en Quem Tem Farelos? el escudero reprende a Apariço por su tardanza: "Como tardaste!« (p. 64). Lazarillo teme una reprensión parecida cuando vuelve tarde: »Pensé que me quería reñir la tardanza« (p. 51), pero esto no ocurre, pues a su amo lo distraen por completo sel pan y las tripas que Lazarillo trae »en cabo de la halda«: »Mostró buen semblante...« (p. 51). En las páginas anteriores hemos sugerido algunos cambios parecidos. 
relos? correspondería el gran mérito de haber proporcionado muchos importantes incitamientos y sugerencias $\mathrm{y}$, claro está, la aún mayor distinción de contener el primer retrato completo del pundonoroso y famélico escudero. $\left(¿ 1505\right.$ ? $^{47}$ en las literaturas ibéricas, que en su propio contexto literario y dramático no es menos original e interesante que el que apreciamos en Lazarillo de Tormes.

${ }^{47}$ Es posible que Quem Tem Farelos? se haya escrito en 1515, como sugieren algunos eruditos, pero en la rúbrica de la obra se indica 1505 como año de composición. (Veáse: Gil Vicente: Obras Completas, Porto; Livraria Civilização, ed. de Alvaro Julio da Costa Pimpão, 1962, pp. 550-551). 